\title{
O escritor da pena feiticeira: João Köpke (1852-1926)
}

Norma Sandra de Almeida Ferreira ${ }^{1}$

\section{Resumo}

No acervo pessoal da família Köpke, foram localizados o manuscrito Versos para os pequeninos (s.d.) e um exemplar impresso de Locuções, proloquios e pensamentos (1915), ambos de autoria de João Köpke (1852-1926). Neste artigo, empreendemos um estudo exploratório dessas obras na perspectiva da história cultural, em duas direções investigativas distintas e que se complementam. A primeira, um estudo de cunho descritivo, como forma de apresentar as obras ao leitor em sua materialidade; a segunda, um trabalho de natureza mais analítica e interpretativa, interrogando como essas obras se constituem em determinada configuração composicional para seus leitores, situandoas no contexto educacional e cultural em que foram produzidas. Concluímos que Versos para os pequeninos e Locuções, proloquios e pensamentos apresentam configurações composicionais bastante singulares em relação à produção impressa destinada à escola, no período compreendido entre o final do século XIX e o início do XX, e que o papel de seu autor precisa ser melhor explorado no interior da literatura didática. Essas obras, pouco estudadas pelos pesquisadores, nos oferecem uma imagem de João Köpke como um escritor que produz um trabalho intencional, tanto com a linguagem quanto com a criação de um projeto visual-editorial em que se instala o texto, extrapolando o seu conteúdo e as práticas escolares tradicionalmente previstas para a formação de valores morais para a criança.

\section{Palavras-chave}

João Köpke - Livros escolares - Educação literária - Ensino da língua.

\section{The sorcerous-penned writer: João Köpke (1852-1926)}

\section{Abstract}

João Köpke's manuscript "Versos para os pequeninos" (Verses for the little ones n.d.) and a printed copy of his Locuções, Proloquios e Pensamentos (Locutions, Adages and Thoughts - 1915) were found amidst his family's personal collection. This paper presents an exploratory study of both writings in the perspective of Cultural History. It

\footnotetext{
1- Universidade Estadual de Campinas, Campinas, SP, Brasil.

Contato: normasandra@yahoo.com.br
}

DOl: http://dx.doi.org/10.1590/S1678-4634201709161585 
follows two distinct yet complementary investigative lines: a descriptive study introduces the readers to the materiality of the works, while a more analytical and interpretative analysis raises questions about how they were arranged into a given composition for their readers and situates them in the educational and cultural context in which they were produced. It is concluded that Versos para os pequeninos and Locuções, Proloquios e Pensamentos fairly present unique compositional forms when compared to the printed production intended for schools at the turn of the 20th century and that their author's role within didactic literature needs to be further explored. Little studied by researchers, these writings show João Köpke as a writer who deliberately works with both language and the creation of a visual/editorial project fitted to his text to transcend contents and the school practices traditionally meant to instil moral values in children.

\section{Keywords}

João Köpke - Schoolbooks - Literary education - Language teaching.

Se a leitura, conforme Certeau (1994, p. 270) “[...] não tem garantias contra o desgaste do tempo" e nem "conserva, ou conserva mal a sua posse", o livro é um objeto que pode me devolver a ilusão da leitura "perdida"; oferecer a oportunidade de conferir, comprovar, retomar algo que parece ter ficado da leitura; dar a chance de descobrir que a cada leitura algo novo e velho se (re)compõe produzindo sentidos, inteligibilidades do mundo e de nós mesmos. E não é (apenas) pelo seu conteúdo, pelo enredo, pelo estilo do autor que os livros nos convidam à leitura, mas também pela edição, pela capa, cor, textura do papel e tipo de letra, pelo cheiro. 0 livro convoca sentimentos, valores, ideias, palavras, como nos mostra a pesquisa de Goulart (2009), que procura entender por que pessoas mais idosas guardam, por quase toda a vida, um livro de leitura usado na escola no tempo de criança.

Livros têm uma história, nem sempre a mesma em todo tempo e lugar². Esses objetos circulam de mão em mão, cruzam fronteiras, ganham formas e usos distintos pelos seus fabricadores e por seus leitores. Em sua materialidade, indiciam modos previstos para sua leitura, produzem representações de leitores pressupostos, assim como permitem identificar como, em diferentes lugares e momentos, uma determinada realidade social é construída, pensada, dada a ler, num campo de concorrências e de competições cujos desafios se enunciam em termos de poder e de dominação (CHARTIER, 1990).

Livros podem ser interrogados, porque parte da história dos próprios livros e dos homens que (re)criam e se apropriam desse objeto também pode ser escrita, reescrita, reavaliada, em outros aspectos ainda não investigados. Quando interrogados como objeto cultural e ideológico produzido, manufaturado e difundido segundo uma lógica comercial e industrial (CHOPPIN, 2002), os livros ganham novas dimensões, porque isso implica a possibilidade de compreensão de uma rede formada por relações de poder e de decisão,

2- Segundo Darnton (1990, p. 147), a "leitura tem uma história. Não foi sempre e em toda a parte a mesma". 
em disputa e em tensão, entre os homens quanto aos seus usos e finalidades nos campos da produção, recepção, circulação.

Nos últimos trinta anos, pesquisas centradas na escrita da história dos livros, da leitura e de leitores avolumaram-se, impulsionadas principalmente pelos estudos trazidos por Roger Chartier (1990); Robert Darnton (1990); Guglielmo Cavallo e Roger Chartier (1999), entre outros.

No Brasil, os trabalhos de Pfromm Neto (1974), Lajolo e Zilberman (1988; 1999), Abreu (2003), Bragança e Abreu (2010), Hallewell (2005) e Arroyo (1990) têm contribuído para a escrita da história dos livros e da leitura escolar, dedicando-se a analisá-los ora sob o prisma de seus atores (escritores, livreiros, editores, leitores), ora pelos espaços demarcados de produção e circulação (editoras, livrarias, bibliotecas, gabinetes de leitura, escolas), ora pelas suas formas (pergaminhos, paleógrafos, manuscritos, impressos, digitais etc.), e ainda pelos usos e apropriações que indicam sua posse pelos seus proprietários.

No interior dessa produção, registra-se um interesse especial da história da educação e do ensino pelos livros escolares, o que particularmente nos interessa neste artigo, assim como a outros pesquisadores, como Bittencourt (1993); Batista e Galvão (2009); Frade (2010a; 2010b); Razzini (2000); Oliveira e Souza (2000); Peres e Tambara (2003), entre outros.

Trata-se de uma produção que toma o livro ora como fonte, ora como objeto, ou ainda em ambas as perspectivas. Segundo Batista e Galvão (2009, p. 15-16), a grande maioria desses estudos voltam-se para os livros escolares como fontes, privilegiando a compreensão de questões relacionadas ao ensino de conteúdos disciplinares, aos processos da escolarização na construção dos saberes, na produção de práticas escolares com a leitura:

[...] uma análise de suas ilustrações e conteúdos, desvinculados, em geral, dos condicionamentos técnicos, econômicos, pedagógicos e sociais desse objeto. [...] Eles são, portanto, objetos por meio dos quais se pode buscar construir a história dos modos de conceber, pelo Estado, a formação ideológica da criança, bem como dos processos pelos quais a escola constrói sua cultura, saber e práticas.

Desconsiderando essas dimensões técnicas e econômicas que norteiam e fazem parte da produção, recepção e circulação dos livros, esses trabalhos geralmente demonstram uma excessiva tendência para o estudo dos conteúdos (ideológicos), desprezando a questão do suporte - em suas diferentes edições e projetos editoriais - em que o texto se apresenta ao leitor, e das representações e práticas inscritas na materialidade do objeto (CHARTIER, 1990). Esses estudos têm priorizado principalmente as obras que fundaram um modo canônico no ensino da língua, que firmaram uma tradição na formação de várias gerações de leitores, que são marcos da organização da escola republicana e das propostas pedagógicas a serem implementadas (BATISTA; GALVÃO, 2009).

Neste texto, apresentamos e descrevemos duas obras de João Köpke (1852-1926), marcando distinções em relação a alguns desses estudos, uma vez que essas obras: 1) são pouco conhecidas e exploradas no meio acadêmico; 2) serão interrogadas não só pelo seu conteúdo, mas principalmente pelo projeto visual e editorial em que se apresentam aos leitores; 3) podem colocar sob outro enfoque a visão formativa depreendida nos trabalhos 
trazidos pela história da educação e da literatura para crianças, sugerindo um autor mais lúdico na configuração composicional de seus livros.

\section{Intenções e propósitos}

Nossa intenção neste texto é aproximar duas obras produzidas por João Köpke, buscando algumas singularidades nos projetos editoriais e textuais em que elas se apresentam em relação às demais também escritas por esse autor e em relação à produção impressa voltada para atender a demanda escolar no mesmo período.

Selecionamos uma obra impressa, Locuções, proloquios e pensamentos ampliação do vocabulario e exercicio de memoria para usos das escolas primarias ${ }^{3}$ (1915) e outra, manuscrita, Versos para os pequeninos (s.d.). Ambas têm sido pouco exploradas analiticamente por outros pesquisadores, ainda que a primeira seja citada por vários (PANIZZOLO, 2006; RIBEIRO, 2001; SANTOS, 2013) e que a segunda faça parte de uma pesquisa maior desenvolvida pela autora do presente texto ${ }^{4}$.

Locuções, proloquios e pensamentos é o sexto livro que compõe o Curso da língua materna - Notas para direcção (1892), conforme indicação do próprio autor em seu prefácio. Locuções, proloquios e pensamentos traz 592 textos, apresentados em um projeto editorial sofisticado, no sentido de que o livro tem tamanho maior $(25 \mathrm{~cm} \times 16 \mathrm{~cm})$ que o usual para os livros infantis da época, capa cartonada e folhas de papel de melhor qualidade (acetinadas).

Suas ilustrações são reproduções de caricaturas, 21 delas assinadas por R. Pederneiras (1874-1954) e 25 por J. Carlos (1884-1950), chargistas brasileiros que publicaram em periódicos importantes do Rio de Janeiro do século XIX, como Fon-Fon, O Malho, TicoTico, Jornal do Brasil. Na capa, seus nomes aparecem logo abaixo do nome do autor, talvez, como estratégia editorial que busca valorizar a obra pela qualidade e reconhecimento que têm esses ilustradores junto à sociedade daquela época.

Figura 1- Capa de Locuções, proloquios e pensamentos (KÖPKE, 1915)

Fonte: acervo da família Köpke.

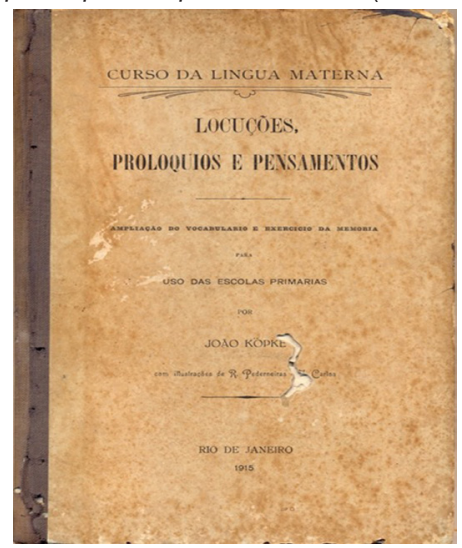

3- 0 título e fragmentos retirados do livro obedecem à grafia da época de sua publicação.

4- Parte da análise e escrita desse texto encontra-se melhor fundamentada na pesquisa intitulada Um estudo sobre "Versos para os pequeninos", manuscrito de João Köpke, de Ferreira, 2014. 
Versos para os pequeninos, na versão manuscrita em que se apresenta, tem como suporte um grande caderno de 54 folhas, sem capa, de formato retangular $(35 \mathrm{~cm} \mathrm{x}$ $23,5 \mathrm{~cm})$. Um tanto esfacelado pelo tempo, o caderno nos lembra aqueles utilizados por escriturários em cartórios ou em secretarias para registro de informações. Trata-se de uma coletânea composta por 24 poemas criados pelo próprio João Köpke e acompanhados de 24 estampas - xilogravuras ou litogravuras - de tamanho $11 \mathrm{~cm}$ x $8 \mathrm{~cm}$, possivelmente reproduções, em tamanho menor, das "pranchas ilustradas" (PIZA, 2008) utilizadas no ambiente escolar.

Locuções, proloquios e pensamentos e Versos para os pequeninos parecem ter em comum o fato de que embora tenham destinação de uso escolar prevista, não alcançaram o mesmo estatuto que as demais obras de João Köpke.

Como sabemos, João Köpke publicou, nas duas últimas décadas do século XIX, cinco dos seis Livros de leituras moraes e instructivas que compõem o Curso da Língua Materna - Notas para a sua direcção, além de livros avulsos, como Leituras práticas, Fábulas, A grande pátria. Principalmente os Livros de leituras moraes foram aprovados para uso nas escolas públicas em São Paulo e no Rio de Janeiro e, segundo Meneses (1981), alguns registraram "mais de setenta [edições] até 1927 e com incessantes revisões do autor" (s/p). Também, neste período, editou as cartilhas analíticas, $O$ Livro infantil e 0 livro das mães (FERREIRA, 2014, 2015). Seus livros de leitura eram editados, de forma pronta e rápida, pela Teixeira \& Irmãos, conforme podemos ler em Curso da Lingua Materna sobre edições e reedições "à venda nas principaes livrarias do Rio de Janeiro e em todos os estados da Republica”, além da indicação dos próximos lançamentos, "em breve” (KÖPKE, 1892, s/p).

No entanto, a obra impressa - Locuções, proloquios e pensamentos - parece ter tido apenas uma edição e não traz qualquer indicação do nome da editora ou casa impressora que a publicou. Há também um atraso entre sua efetiva edição, em 1915, e o anúncio feito pelo autor - conforme lemos na "Conclusão" do Curso da Lingua materna: "Trabalhamos na confecção do $4^{\circ}$ [livro] que, dentro de mezes, terá chegado à conclusão. Em seguida, escreveremos o $5^{\circ}$ e $6^{\circ} \mathrm{E}$, com elles, a serie estará terminada” (KÖPKE, 1892, p. 105).

Pelas informações ligadas às suas condições de produção, encontramos nas páginas iniciais da obra uma advertência impressa: "Serão reputados contrafacção os exemplares que não forem rubricados pelo autor ou seu representante legalmente autorisado"; uma vinheta impressa que tem em seu centro, em letra cursiva, " $n^{\circ}$. 996"; a indicação impressa: "0 autor", acompanhada da assinatura, de próprio punho, de João Köpke. Tais informações remetem a uma personalização da obra, carregada de valorização da autoria e de preocupação com a legalidade da edição. São ainda indícios de que essa publicação tenha sido um investimento do próprio autor, como prometera fazê-lo também com as Cartilhas 1 e 2 sobre o método analítico (SANTOS, 2013).

A segunda, Versos para os pequeninos, traz em sua primeira página, denominada por nós como página de rosto (FERREIRA, 2014), algumas das condições de produção desse material, como: título (Versos para os pequeninos); local de produção (Instituto H. Köpke); autor ("Pelo Director”); epígrafe ("Quem faz o que póde, tem feito quanto deve./ Quem póde mais, que suppra as suas defi-/ciencias, pois essa é a melhor das críticas”).

0 manuscrito parece ser um boneco de livro, cuidadosamente elaborado nos mínimos detalhes, e pode ter sido produzido, portanto, no período que João Köpke esteve 
na direção do Instituto Henrique Köpke (1886-1898), no Rio de Janeiro. 0 conjunto de poemas da obra está dividido em duas partes, separadas por uma folha em branco. Há também páginas em branco no início, à espera de uma apresentação da obra.

A presença de uma epígrafe - tão artesanalmente trabalhada: em letras cursivas, no canto esquerdo, disposta como se fossem versos - pode ser um indício de que esse material previa leitores mais distantes e menos circunscritos ao Instituto Henrique Köpke. A escolha de uma epígrafe que não tem indicação de autoria, mas que vem entre aspas, aciona nossa memória cultural pelos ditos populares, especialmente seu primeiro verso "Quem faz o que póde, tem feito quanto deve".

0 capricho na composição da página de rosto, assim como todo o cuidado na forma como esse manuscrito se apresenta para nós, são indícios, entre outros, de um possível desejo do autor de publicá-la.

Figura 2 - Página de rosto de Versos para os Pequeninos (s.d.)

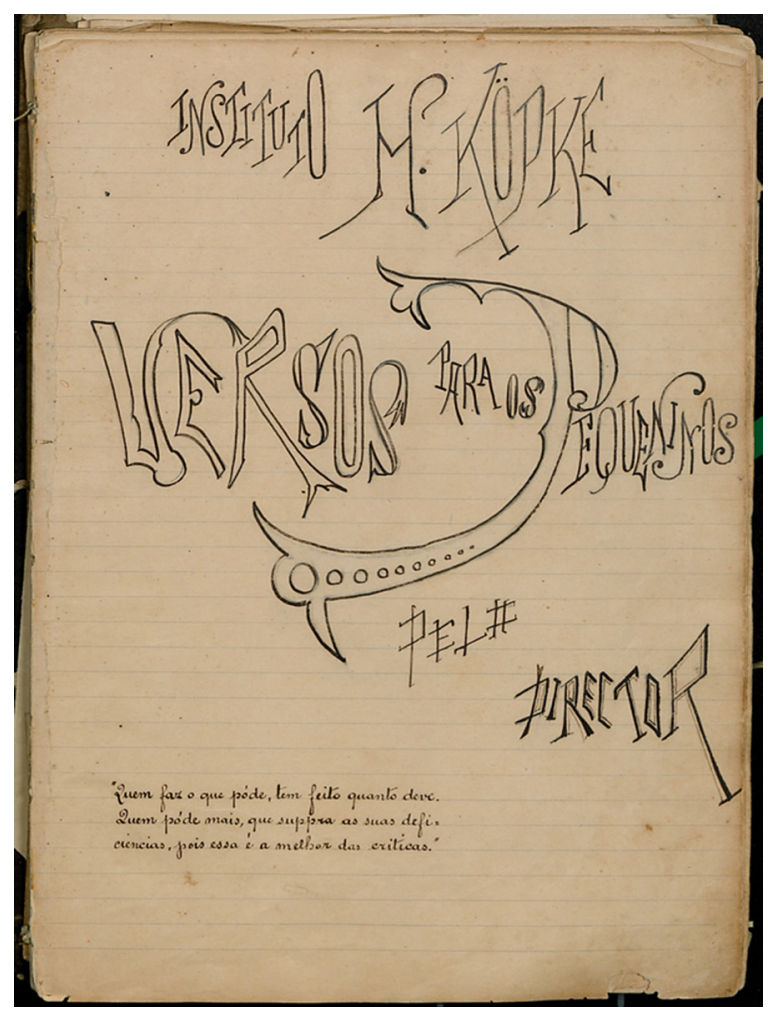

Fonte: acervo da família Köpke.

Nessa página de rosto, com maior ênfase do que nas demais, o leitor encontra uma visualidade que amalgama os campos lexical e ornamental, a escrita e o desenho. Nela, as informações sobre a obra estão colocadas de forma lúdica e, sobretudo, inusitada. Traços 
das letras "engordam", se alongam, ficam fininhos, fazem curvas. São letras cortadas e animadas: têm pés, pernas, rabo, cabeça, mãos. São desobedientes no que se refere à horizontalidade de uma linha e à homogeneidade de traçado convencional da letra de fôrma maiúscula ou cursiva. "Teria o autor, no tratamento das letras, sido orientado por uma concepção de linguagem que não dissocia forma, conteúdo e leitor a quem a obra se destina?" (FERREIRA, 2014, p. 157).

De qualquer modo, entre a produção dessas duas obras pode ter decorrido um espaço de tempo em torno de vinte anos. Versos para os pequeninos parece ter sido produzido na época em que grande parte das obras de João Köpke estava sendo editada pela Francisco Alves, atendendo a um ambiente de demanda escolar pelo material de leitura, no final do século XIX (HILSDORF, 1986). Já a data de publicação de Locuções, proloquios e pensamentos, em 1915, ao contrário, nos remete a um tempo em que Köpke dedica-se à função de revisar as edições de seus livros, já que desistira de sua profıssão como professor e diretor de escolas particulares, assumindo o cargo de oficial de registro real e de hipoteca, no Cartório de Registro de Imóveis do $1^{\circ}$ Distrito do Rio de Janeiro, por volta de 1898.

Por outro lado, podemos constatar que essas duas obras apresentam uma configuração composicional estritamente ligada à concepção de linguagem e de ensino da língua materna bem singular em relação à produção destinada à escola no mesmo período. Uma configuração composicional entendida por nós como constituída pelos aspectos discursivos (o quê, como, onde, quando, por quê, para quê, quem e para quem) propostos por Bakhtin (2003) e pelo suporte que os sustentam (CHARTIER, 1990), articuladamente organizados e mutuamente dependentes em um determinado objeto cultural: um livro. E, talvez, a configuração composicional das obras analisadas possa ter sido responsável pela falta de interesse do mercado editorial voltado para o leitor escolar, sob novas orientações pedagógicas oriundas da Escola Normal de São Paulo (MORTATTI, 2000).

\section{Uma visão pelos estudos}

Pesquisadoras, como por exemplo, Mortatti (2000); Laguna (2003); Panizzolo (2006); Santos (2013), já atribuíram à produção de João Köpke uma vinculação com o homem republicano e progressista que foi, educador defensor de um ensino da língua materna pelo método intuitivo e positivista, vinculado a uma rede de intelectuais, especialmente aqueles formados pela Faculdade de Direito do Largo São Francisco, em São Paulo. Panizzolo (2006), por exemplo, dedica-se a examinar os livros de leitura impressos de Köpke, situando-os no embate com outros autores de livros didáticos sobre as formas ideais de criação de um livro de leitura e a construção de um papel da escola no período entresséculos:

Por meio de seus livros de leitura, Köpke leva ao termo e ao cabo um projeto civilizador - pela via da leitura - faria o progresso do país. Para a elite intelectual da qual Köpke fazia parte, à escola cabia a importante missão de transformar habitantes em povo, regenerar o trabalhador e salvaguardar o organismo nacional. Enfım, construir uma nação. (PANIZZOLO, 2006, p. 315). 
Em sua preciosa análise, Panizzolo (2006) destaca, nas lições dos livros, o enaltecimento do bom comportamento escolar a ser desenvolvido pela criança e a valorização de sentimentos como a honestidade, a persistência, a amizade, o respeito aos mais velhos e a solidariedade para com o próximo, entre outros.

Autores como Arroyo (1990), Lajolo e Zilberman (1988), Pfromm Neto (1974), D’Ávila (1964), entre outros, também já delinearam o lugar ocupado por João Köpke no panorama da literatura escolar, visto predominantemente pela sua função formativa ética e moral - junto ao leitor infantil e por ter sido responsável pela promoção de práticas de leitura menos enfadonhas e mais prazerosas às crianças.

Segundo (FERREIRA, 2014), ao imprimir a presença de João Köpke na história dos livros para crianças, esses estudos têm em comum o fato de o colocarem como um autoreducador, que lançou a "semente" da literatura infantil, pioneiro da produção didática que prepararia o campo para o gênero literatura infantil com sua obra Fábulas (1910) e Livro das crianças (em parceria com Zalina Rolim, 1897), ao lado dos escritores Olavo Bilac (Poesias infantis), Francisca Julia e Julio da Silva (Alma infantil), de Júlia Lopes de Almeida e Adelina Lopes Vieira (Contos infantis), entre outros. Obras situadas em um período em que a distinção entre literatura infantil e literatura didática ou escolar não é explícita e tampouco nítida. Na denominação literatura didática ${ }^{5}$ cabe praticamente tudo: livros para utilização imediata na área escolar, com a intenção de diversão ou de aprendizado, para estudo ou obrigações escolares (ARROYO, 1990), oscilando entre um trato mais ou menos estético com a linguagem; entre maior ou menor ênfase intencional em instruir ou formar.

Desses estudos, o de Antonio D’Ávila (1964) é o único a ressaltar não só a qualidade formativa da obra de João Köpke pelos ensinamentos dos valores morais e pela retidão de comportamento, mas também pelo efeito de enredamento produzido no leitor pelas tramas, que levam à identificação com os heróis, pelo jogo bem-humorado, pela indistinção entre realidade e ficção - própria do modo infantil de perceber o mundo.

Neste texto, aproximamo-nos de D'Ávila ${ }^{6}$ ao empreendermos nosso estudo exploratório em torno de Locuções, proloquios e pensamentos e Versos para os pequeninos. Acreditamos que essas duas obras podem nos ajudar a construir aspectos da imagem de Köpke e de sua produção ainda pouco explorados: um escritor menos sisudo, bemhumorado, laborioso e caprichoso com suas obras e extremamente coerente com os projetos pedagógicos e literários em que elas se inserem. Um escritor que produz seu material para usos escolares de acordo com um programa instituído por ele próprio, mas que interfere na forma visual e tipográfica de apresentação desse material, contrariando as ideias trazidas por Chartier (1990) de que os escritores não escrevem livros, mas textos ${ }^{7}$.

Apoiada principalmente em estudo desenvolvido por Ferreira (2014), levantamos como hipótese que a configuração composicional da produção de João Köpke, tal como ela se constitui quanto ao uso da linguagem, à temática, ao leitor pressuposto, à prática

5- Segundo Choppin (2002), a definição do manual escolar varia segundo os lugares, as épocas, os suportes, os níveis e as matérias de ensino, os usos e finalidades a que se destinam, segundo os contextos político, econômico, social, cultural, estético.

6 - Assumimos, no título e em alguns subtítulos deste artigo, expressões cunhadas por D’Ávila (1964) ao se referir a João Köpke.

7 - Ver estudos já empreendidos com livros de leitura seriados e publicados pela Francisco Alves (FRADE, 2010; OLIVEIRA; SOUZA, 2000; ORIANI, 2010). 
de leitura prevista, à finalidade da leitura e à sua materialidade, exige ainda um trabalho mais analítico e interpretativo, ancorado na perspectiva da história cultural (CHARTIER, 1990). E complementamos D’Ávila, destacando que a configuração composicional das obras de João Köpke ancora-se intencionalmente em uma concepção de linguagem que orienta o ensino da língua materna, em que "[...] o discurso e a palavra são a realidade para o que aprende, e do discurso e da palavra - não da sílaba, nem da letra se há de subir à arte da leitura" (KÖPKE, 1902, p. 589).

Desse modo, apresentamos essas duas obras, destacando em sua configuração composicional dois aspectos: a presença da cultura oral e o ineditismo dos projetos editoriais e pedagógicos.

\section{Presença da cultura oral}

Locuções, proloquios e pensamentos e Versos para os pequeninos são duas obras com resquícios da cultura oral, aquela que, pela forma de transmissão, integra o cotidiano do indivíduo desde muito cedo e que está presente, principalmente, em ambientes menos formais, mantendo-se viva por várias gerações.

Locuções, proloquios e pensamentos reúne pensamentos, prolóquios e locuções, na forma de quadrinhas e versos, gêneros que, pelo pragmatismo no contexto de inculcar bons modos a alguém, embora inscritos no uso da linguagem figurada, produzem certa leveza, por causa da rima e ritmo neles empregados, assegurando ainda a retenção dos conceitos.

Vejamos um pensamento retirado dessa obra e assinado por Berni: "Si falta a força do pulso,/ Ao velho, que a idade afraca,/Sobra-lhe a força do tino,/ Que guia, harmoniza e aplaca." (KÖPKE, 1915, p. 48). Ou, ainda, a seguinte locução, que pelo tema nos lembra o poema "Canção do Tamoio", de Gonçalves Dias (1823-1864): "Inda que vejas a morte,/ não desertes do teu posto/ pois, mais que medo, anniquila/Vergonha que sobe ao rosto" (KÖPKE, 1915, p. 49). Ou então o prolóquio "ninguém larga sem dor o que possue com amor" (KÖPKE, 1915, p. 82).

A segunda obra, Versos para os pequeninos, é composta de poemas, em sua maioria com estrofes de quatro versos, que possuem de quatro a sete sílabas métricas, com uma melodia marcada por rimas também simples, postas no segundo e no quarto versos e seguidas, majoritariamente, de um refrão. Uma estrutura poética muito próxima da que conhecemos hoje como nossa literatura de cordel, ou como literatura menos exigente do ponto de vista rítmico, segundo a crítica literária canônica, como vemos em "Balanço":

Bão-ba-la-lão!/ Meu capitão/ Upa, balanço!/ Bumba no chão!/ Laura, Tonico, / Chico brincando, / Vão no balanço/ Se embalançando./ Bão-ba-la-lão!/ (...) Eis, de repente,/ A corda lashe/ Tudo de costas/ Na areia plashe!/ Bão-ba-la-lão!/ Meu capitão!/ Upa, balanço!/ Bumba no chão!/ Que cambalhota!/ Mas ninguém chora!/ Levantam rindo/ E vão-se embora!/ (...) (KÖPKE, s.d., p. 5).

Não se vê, pelo menos para essas duas obras, o propósito de apresentar a poesia dos grandes clássicos da cultura escrita (autores brasileiros e portugueses) como modelares para o ensino da língua materna, como João Köpke o faz, por exemplo, em Florilégio contemporâneo (1900b). 
Sua preocupação pode ser desdobrada em duas direções que, em comum, buscam um uso da linguagem mais apropriado - em versos - ao seu leitor. Uma primeira, trazer a tradição da cultura oral pelo uso de uma linguagem mais simples, sem estorvo, um modo menos abstrato, como convém ao método intuitivo. Uma segunda direção, trazer o que está acumulado na cultura oral pela linguagem que vem pelos sentidos (ouvido), ligados a uma cultura universal. Ambas apreciadas pelos jovens aprendizes, porque seu interesse vem do que lhes é mais próximo, modo de percepção para facilitação da aprendizagem.

A escolha por um gênero que circula na cultura oral, em versos, no caso de Locuções, proloquios e pensamentos é justificada no prefácio feito pelo autor:

\begin{abstract}
Uma outra cousa devo tambem pôr em evidencia: os pensamentos, aqui, collecionados, são de poetas e prosadores, mas apparecem sob a forma de verso, porque me pareceu que, sendo o rithmo e a rima dous poderosos auxiliares da memoria, seria preferivel dar a esses conceitos sob tal forma, assegurando assim a sua retenção, depois de assimilados elles, quer em substancia, quer no valor dos vocabulos, pelas explicações opportunas com que o mestre os ha de esclarecer. (KÖPKE, 1915, p. xvi).
\end{abstract}

Já Versos para os pequeninos faz parte de um programa para o ensino da língua materna que inclui a "iniciação da cultura moral e intelectual pela poesia", em que a palavra oralizada pertence ao gênero lírico, que se imprime no espírito e nos sentimentos da criança (FERREIRA, 2014). Uma proposta que Köpke, em tom professoral, estende a outros escritores, como por ocasião dos lançamentos de Livro das crianças, de Zalina Rolim (1ª ed. 1896) ou de Páginas infantis, de Presciliana Duarte de Almeida (1 $1^{\text {a }}$ ed. 1908). Uma valorização da poesia cantada em versos, para ser ouvida, pois "[...] na música do ritmo e rima, na riqueza dos vocábulos, na memorização do que é belo [...], finalmente apurar, enriquecer e adequar a expressão da linguagem” (KÖPKE, 1914, p. Xxxx).

Talvez tenha sido esse entendimento dado por D’Ávila (1964), quando destaca que João Köpke, acertadamente, deu importância à transição que se dá entre o ouvido e o lido, entre o escrito e o oral, na entrada da criança na escola. Talvez seja uma percepção de que o leitor pressuposto para sua obra encontre maior facilidade na linguagem menos rebuscada e embolada, em versos, como ele próprio justifica, no prefácio de Fábulas para uso das classes de lingua materna do Instituto Henrique Kopke, arranjadas pelo director: “[...] infantil - é isso; fil-o/ p'ra crianças, justamente” (KÖPKE, 1910, p. 5).

Locuções, proloquios e pensamentos faz parte do conteúdo do programa exposto em Curso da Língua materna (1892). Tal conteúdo consta na seção III, denominada "Exercicios do terceiro grau - Composição e Discurso", com a seguinte orientação: "Aplicação dos proloquios. 9 Anno. Explicado o prolóquio, cada aluno inventa um conto ou anedota, em que lhe dê a applicação" (KÖPKE, 1892, p. 100). Ou, ainda, na seção II, intitulada "Exercicios do $2^{\circ}$ Grau - Ampliação do vocabulario pre-escolar e relacionamentos dos vocábulos", capítulo 2, exercício VII: "Explicação de Proloquios e Figuras" (8 Ano), seguido da seguinte orientação: "Nos trechos lidos, ou em relação com elles, será o sentido real dos proloquios e figuras o objecto de explicação cuidadosa [... ]” (KÖPKE, 1892, p. 69).

Nesse caso, o projeto de ensino da língua materna de Köpke fundamenta-se na ideia de que textos em versos facilitam a assimilação do conteúdo e dos conceitos, desenvolvem 
a leitura expressiva, oferecem a ampliação do vocabulário, promovem a dicção correta, dão o "assumpto" para a escrita do conto ou anedota. Um projeto de ensino calcado na arte da retórica, mas que também valoriza "as variantes da mesma ideia e das ideias contrárias” (KÖPKE, 1915, p. Xvi) na produção (oral e escrita), evocadas pelos alunos porque compreendidas, e memorizados os conceitos. São palavras ditas que se fixam na escrita, é o escrito que regressa à oralidade (CHARTIER, 1990).

Em Versos para os pequeninos (s.d.), temos apenas pistas para as práticas de leitura previstas para os poemas. A acentuada musicalidade percebida pelo ritmo das sílabas, pelas rimas, repetições de um mesmo som, aliterações, pela cadência marcada pelas anotações de letra cursiva de João Köpke ${ }^{8}$ indicando alternância de vozes à frente dos versos e no refrão (coro) são indícios de uma proposta de leitura oralizada, leitura encenada, a linguagem em performace (CAVALLO; CHARTIER, 1999).

São duas obras que, inseridas em projetos pedagógicos de ensino da língua materna e de iniciação à literatura pelo autor, são também alinhavadas por uma concepção de linguagem que pressupõe gêneros discursivos para usos escolares presentes em determinados contextos comunicacionais da vida humana (BAKHTIN, 2003).

\section{Projetos inusitados}

Não podemos negar que o projeto pedagógico e instrutivo proposto por João Köpke em Locuções, proloquios e pensamentos e em Versos para os pequeninos se coloca bastante inusitado em relação à produção impressa ${ }^{9}$ do mesmo período destinada à escola.

Para Petrucci (1999), a escritura é para ser lida pela mensagem verbal que encerra no plano analítico-discursivo. Mas é também para ser vista em sua composição de traços, curvas e desenhos, no plano sintético-figurativo.

No caso dessas duas obras, destacamos que os dois planos - o analítico-discursivo e o sintético-figurativo (PETRUCCI, 1999) -, articulam-se entre si, de modo que a sua combinação é uma mistura do que é visto e lido, um contaminado pelo outro. E ainda, a escritura - quer no plano da comunicação (verbal), quer no plano de seu aspecto figurativo - instala-se em um projeto editorial (no impresso) ou visual (no manuscrito) que extrapola o conteúdo das páginas em que se inscreve.

Nesse sentido, o que vemos em cada uma das páginas dessas obras é uma apresentação estética visual intencionalmente cuidada de forma bastante regular e sistemática, que no todo cria um jogo possível de ser interpretado entre conteúdo (assunto tratado) do texto verbal e o da ilustração; entre a disposição visual da escrita e seu conteúdo; um jogo movimentado pelas práticas de leitura e de escrita.

Em Locuções, proloquios e pensamentos (1915), os prolóquios emolduram a página porque estão jogados em cima, em baixo, do lado esquerdo e do direito, de forma centralizada. Dentro da moldura, em letras maiúsculas, lemos: LOCUÇÕES. São sempre

\footnotetext{
8- Em Versos para os pequeninos podem ser vistas também anotações rascunhadas, à lápis, ladeando os poemas. Solicitamos um laudo pericial, cuja conclusão apontou que os poemas são escritos do próprio punho de João Köpke, enquanto que as anotações são de Winckelmann, seu filho (FERREIRA, 2014).

9- Ainda que não saibamos quais intervenções poderiam ter sido impostas se essas obras fossem publicadas por uma grande editora comercial e se contassem com indicação para circular em um universo escolar mais amplo.
} 
três locuções, cada uma delas com quatro versos e rimas do tipo A-B-C-B, que podem ser denominadas "quadrinhas", sem qualquer ligação temática entre elas ou entre os demais textos da mesma página e separadas por discretos clichês tipográficos. A primeira das três locuções presentes na página se inicia com uma letra capitular (FERREIRA, 2014), dando ao conjunto um efeito artístico-artesanal. E, finalmente, abaixo dessas locuções, o título, em caixa-alta: PENSAMENTO, seguido do próprio pensamento, geralmente com autoria reconhecida como pertencente à cultura universal.

Uma diversidade - de nacionalidade, época, campo de conhecimento - muito grande de autores assina os pensamentos, entre eles: Lamartine, Smith, Cowper, Seneca, Plutarco, Byron, Campanella, Gray, J. Good, Elliot, Midleton, Shakespeare, Poepe, Longfellow, Voltaire. Segundo o próprio Köpke, sua escolha recai preferencialmente por autores não nacionais porque "[...] já vários livros didactivos attendem a tal reclamo patriotico, enquanto que, com a feição humana do seu e seu ponto de vista, é elle o primeiro" (KÖPKE, 1915, p. Xvi).

Em uma mesma página identificamos prolóquios e locuções - gêneros ligados ao saber popular, oriundo da experiência prática reconhecida como perene e universal - e pensamentos - que sugerem ao seu usuário uma certa erudição e saber enciclopédico.

Uma opção desse autor por uma tendência de teor cosmopolita, “em cujas páginas não se encontra o Brasil” (D’ÁVILA, 1964, p. 34), em meio a uma literatura escolar que surgia e se firmava em nosso país, de tendência nacionalista, iniciada com Coisas Brasileiras - mal impressa e mal ilustrada - que compõe a série Romão Puiggari, segundo D’Ávila (1964).

Certamente estamos aqui diante do projeto pedagógico do autor que tenciona civilizar, conforme ele próprio coloca:

[...] procuro imbuir o espírito e o coração da infancia e adolescencia em ideias e sentimentos capazes de nortear a conducta no convivio social, afim de que, sempre satisfeito ante a sua consciencia, o indivíduo se premuna contra as ciladas multiplas e multiformes do mal, e collabore symathicamente com os seus similhantes, inspirado nas licçoes de uma altruímo sensato e sincero. (KÖPKE, 1915, p. XV).

Mas cada página estampa um projeto tipográfico esteticamente cuidado, constitutivo do próprio projeto pedagógico idealizado pelo seu autor, quer naquela que registra os textos escritos, quer na preenchida pela caricatura.

A ilustração ganha destaque pelo tamanho, pelo lugar que ocupa na página, pelo gênero que ela representa (caricatura), por ser assinada. A importância dada por Köpke à qualidade, quantidade e função das imagens em um livro pode ser entendida, por exemplo, pelo conselho dado por ele a Zalina Rolim, por ocasião da produção do Livro das Crianças (1897). Ele considerou imprescindível a encomenda das gravuras antecipadamente, para que cada poesia fosse sugerida por uma estampa, para análise e inspiração da jovem poetisa, atrasando inclusive o lançamento da obra (PIZA, 2008, p. 37). Mas, também, conforme ele afırma, as gravuras permitem a "objetivação dos sentimentos e ideias expressos no verso" (KÖPKE, 1896, p. 1) e precedem a leitura e a memorização a ser feita pelas crianças. Assim, as belas estampas encomendadas são fontes inspiradoras para o autor-educador, criteriosamente selecionadas porque são elas, em harmonia com o texto 
que as descreve, que aguçam a observação e incentivam usos da linguagem (KÖPKE, 1896, p. 1), coerentemente planejadas dentro do método intuitivo.

Em Locuções, proloquios e pensamentos, abaixo de cada caricatura há apenas um prolóquio. Na cena exagerada e deformada que sugere ações dos indivíduos em situações embaraçosas e jocosas, representadas pelos traços do caricaturista, temos um efeito de humor. Nos textos, de conteúdo moralizante e educativo, identificamos uma proposta para regular atitudes e condutas sociais, como, por exemplo, "cada qual em sua casa, tem um morto que chorar" (KÖPKE, 1915, p. 105). Entre estes dois campos, o jogo entre o que ridiculariza e o que ensina.

Figura 3 - Locuções, proloquios e pensamentos (Köpke, 1915, p. 104-5)

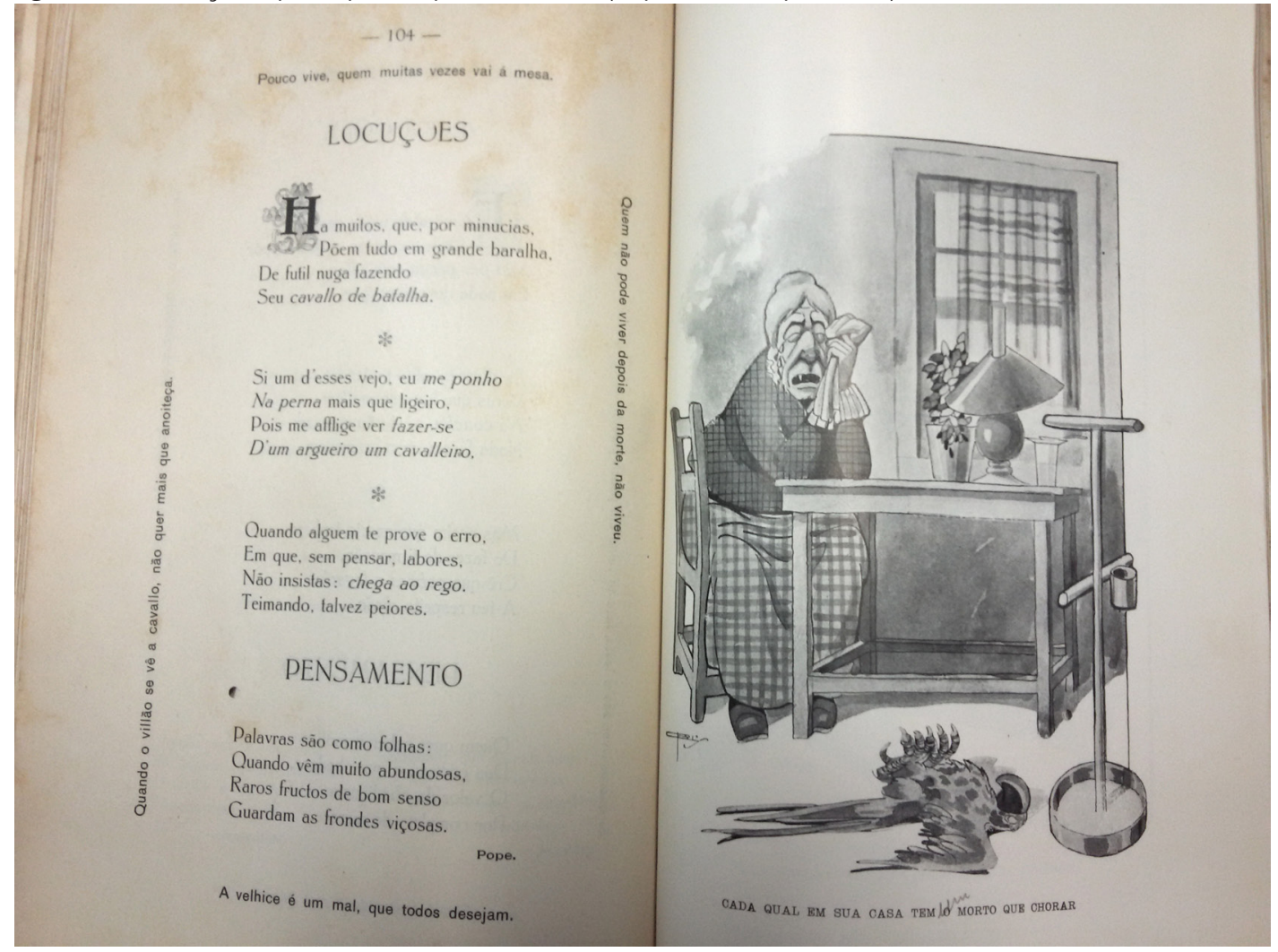

Fonte: acervo da família Köpke.

Lado a lado, caricatura e texto são vistos de imediato e produzem um jogo entre o conteúdo literal (uma senhora chora a morte do papagaio, o louro de estimação) inscrito na caricatura e o conteúdo figurado (ameaça, repreensão, precaução) nos prolóquios, nas locuções e pensamentos, sem que, no entanto, se estabeleçam relações de sentido entre eles.

Não vi nada parecido em nenhum outro livro impresso de Köpke, inclusive os demais que compõem o Curso de Lingua Portuguesa (1892). Mas podemos reconhecer um jogo entre imagem e texto, também na forma manuscrita posta em Versos para os pequeninos. 
Em Versos para os pequeninos, a estampa está situada em uma página e o poema ocupa a que fica ao lado. Como na obra impressa, sob a ilustração, uma legenda (um título/um prolóquio) dá a síntese do conteúdo, orienta um sentido ao leitor, em uma estratégia de continuidade entre os textos e as duas diferentes linguagens.

Em Versos para os pequeninos, as estampas são inspirações para a produção dos poemas descritivo-narrativos, conforme Köpke orienta que Zalina Rolim o faça em seu Livro das crianças (KÖPKE, 1896).

As estampas "bem-comportadas", diferentemente das caricaturas, representam cenários, objetos, crianças, adultos, animais e práticas facilmente associadas à cultura europeia. São cenas de passeios, de brincadeiras e de estripulias típicas do universo infantil, de apreciação da natureza e de situações domésticas.

Ao contrário de Locuções, proloquios e pensamentos, os textos criados por João Köpke para Versos para os pequeninos são pouco moralizantes e disciplinadores. Em sua grande maioria, os poemas propõem cenas engraçadas, falas que imitam a representação da linguagem e do modo de pensar da criança. Quase uma irreverência. ${ }^{10}$ Animais (gatinhos), por exemplo, se divertem, ignorando a razão e os conselhos da mamãe, abandonam a leitura atenta e correta, ignoram seus deveres e o saber da escola para pensar na comida (um rato), como em "Travessos” (KÖPKE, s/d; p. 33).

Vejamos, por exemplo, a ilustração e o poema que acompanham o título "A Lua".

Figura 4 - "A Lua", de Versos para os pequeninos (Köpke, s.d., p. 6-7)

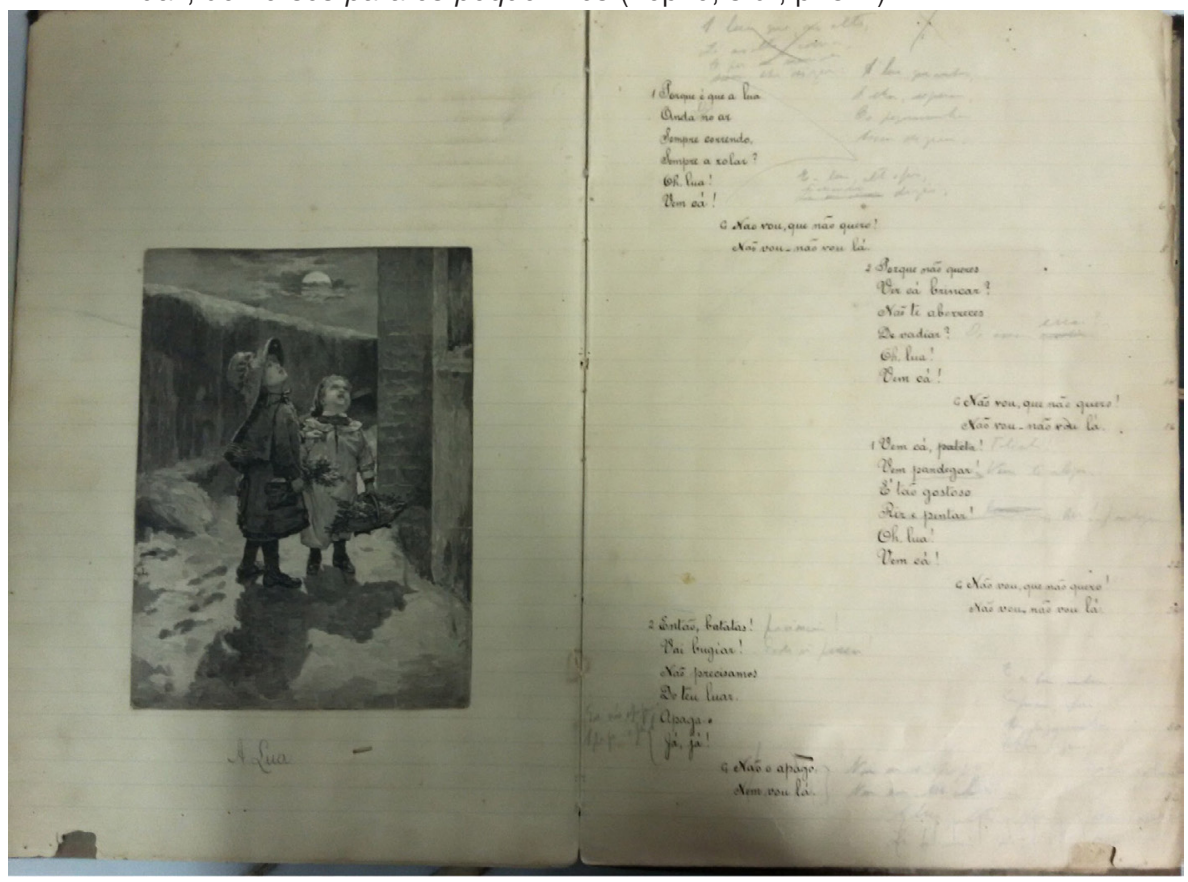

Fonte: acervo da família Köpke.

10 - A mesma estampa presente, por exemplo, em Livro das Crianças (1886, $1^{\text {a }}$ edição), de Zalina Rolim, traz, diferentemente do texto de Köpke, um poema que se propõe a inspirar a criança por meio de atitudes exemplares (FERREIRA, 2014; 2015). 
Conforme (FERREIRA, 2014), a estampa apresenta crianças bem vestidas, bem agasalhadas, bem calçadas, do lado de fora de sua casa, que olham para cima, talvez para algo que lhes chamou atenção. Ambas carregam flores, segurando-as nas mãos e guardando-as em uma cesta. O leitor diante da estampa vê a lua, entre nuvens, que ilumina a noite e as crianças.

Segundo Ferreira (2014), nesse poema, a lua é caracterizada pelos seguintes verbos, que indicam as possíveis ações a ela atribuídas: andar, brincar, correr, rolar, vadiar, pandegar, ir, conversar. Personificada no poema, a lua conversa provavelmente com as crianças, que a chamam: "Olha, Lua!/ Vem cá!”, e, na forma de refrão, ela assim responde: “não vou, não quero!"/ não vou - não vou lá."

0 poema dialogado talvez possa ser uma estratégia para ensinar um conteúdo (um fenômeno da natureza) de modo a colaborar na facilitação da impressão e animar a atenção do educando para o assunto tratado no texto, recurso também presente em A grande pátria, de João Köpke (1900a). Ou, ainda, para auxiliar na leitura expressiva ou na memorização dos versos, independentemente do seu conteúdo, o que também ajuda na assimilação da ideia. Uma prática no ensino da língua materna em que a ortografia memorizada substitui o ditado, "[...] mandando-lhes que escrevam os versos, decorarem para recitação" para que prestando atenção ao escrito, fixem e aprendam a grafia correta, habituando-se "a obedecer ao metro e à rima”, uma iniciação à arte poética (KÖPKE, 1915, p. Xvii).

0 ritmo dado pelo refrão, além das rimas e da regularidade no número das sílabas e as anotações indicando alternância de vozes, criam a musicalidade do texto e sugerem uma atmosfera de disputa oral, o que dinamiza o uso da linguagem, algo bem distinto da prática de declamação feita por uma única pessoa ou de um poema lido silenciosamente.

A recusa da lua em atender as crianças altera o tom amistoso mantido até então. 0 final bem-humorado é praticamente inaceitável, se pensarmos que o leitor pressuposto para o poema é o infantil, que, com a leitura, deveria aprender bons modos, segundo o que registram os historiadores da literatura infantil (ARROYO, 1990; LAJOLO; ZILBERMAN, 1988) e os da história da educação (PANIZZOLO, 2006; LAGUNA, 2003) como objetivos da literatura destinada às crianças neste período histórico. As crianças, irritadas, ordenam: “Então, batatas!/ Vai bugiar!? Não precisamos/ do teu luar./ Apaga/ já, já!” - e a lua, desobediente, a elas responde: "Não apago,/ nem vou lá."

A disposição visual da escrita cursiva do poema na página (que se mantém, no interior de toda a obra) merece destaque para análise. Em Versos para os pequeninos, estrofes são esticadas ou ganham desenho côncavo; versos dançam, amontoam-se, descem, sobem pelas linhas pautadas, sugerindo, no desalinhamento alinhado, uma brincadeira do autor, uma disposição lúdica dos poemas nas folhas do caderno.

Um jogo deliberado, que pode decorrer de uma intencionalidade estética, funcionando, sobretudo como estratégia visualmente inventiva e bem-humorada, que contempla o leitor pressuposto e antecipa/dialoga com o conteúdo do que virá depois e do que expressa (FERREIRA, 2014). 0 poema "A Lua", por exemplo, permite interrogações sobre o seu desenho visual e o assunto a ele ligado: o texto jogado sobre a folha em branco lembra a trajetória da lua, que se movimenta no céu, como diz o poema? 0 texto desenha o formato de uma "lua decrescente"? 
Tanto em Versos para os pequeninos, quanto em Locuções, proloquios e pensamentos, o que constatamos é que João Köpke é um escritor orientado por uma concepção de linguagem que não dissocia a forma (materialidade visual/tipográfica), o conteúdo (assunto), o uso da linguagem (em versos), as práticas escolares de leitura, a finalidade e intenções do autor e o leitor ao qual a obra se destina. Formas de concretizar seu projeto de ensino da língua materna, considerando que, segundo ele, a produção escolar disponível no mercado não lhe permite a execução do seu programa previsto (KÖPKE, 1892).

\section{“Instrutivas e morais, as suas histórias foram as melhores de nossos livros de ontem" (D'ÁVILA,1964, p. 35)}

Locuções, proloquios e pensamentos e Versos para os pequeninos são configurações composicionais um tanto originais para a época e para o mercado editorial disposto a atender uma demanda escolar.

Sem dúvida alguma, estamos diante de um autor que propõe algo bastante distinto e que parece ter ficado, pelo menos em relação a essas duas obras, "à margem de uma vasta e variada literatura escolar, pragmática, sentimental e nacionalista” (D’ÁVILA, 1961, p. 35).

Um autor que impõe em suas produções uma configuração composicional constituída igualmente pelo projeto tipográfico-visual-formal e pelo conteúdo a ser assimilado, que pressupõe práticas com usos da linguagem (de transformação, imitação, invenção) e de leitura expressiva, de memorização, de recitação, de encenação para o leitor escolar. Uma configuração composicional que integra o projeto pedagógico para o ensino da língua materna calcado no método intuitivo e na iniciação à literatura pela retórica, não apenas pelo assunto que é nela tratado.

Um autor que lida com a linguagem não apenas como veículo de informação e de conteúdo a inculcar na criança, mas que, sobretudo, propõe um jogo instaurado nas práticas escolares e instrutivas e configurado na linguagem que acolhe seu interlocutor; um modo de expressão de desejos e intenções do autor, que, no todo, busca produzir certos efeitos de sentido que fogem daquele objetivo de apenas civilizar as crianças.

Um autor que, com sua pena, enfeitiçou milhares de brasileiros e levou consigo o segredo de uma arte pessoal: "Talvez o seu melhor epitáfio” (D’ÁVILA, 1964, p. 272).

\section{Referências}

ABREU, Márcia. Os caminhos dos livros. Campinas: Mercado de Letras: Associação de Leitura do Brasil, 2003.

ARROYO, Leonardo. Literatura infantil brasileira. São Paulo: Melhoramentos, 1990.

BATISTA, Antonio Augusto Gomes; GALVÃO, Ana Maria Oliveira. Livros escolares de leitura no Brasil: elementos para uma história. Campinas: Mercado de Letras, 2009.

BAKHTIN, Mikhail. Estética da criação verbal. São Paulo: Martins Fontes, 2003. 
BITTENCOURT, Circe Maria Fernandes. Livro didático e conhecimento histórico, uma história do saber escolar, 1993. Tese (Doutorado) - Faculdade de Filosofia, Letras e Ciências Humanas da Universidade de São Paulo, São Paulo, 1993.

BRAGANÇA, Aníba; ABREU, Marcia (Org.). Impresso no Brasil: dois séculos de livros brasileiros. São Paulo: Unesp, 2010.

CAVALLO, Guglielmo; CHARTIER, Roger (Org.). História da leitura no mundo ocidental. Tradução de Fúlvia M. L. Moretto. São Paulo: Ática, 1999.

CERTEAU, Michel de. A invenção do cotidiano. Petrópolis: Vozes, 1994.

CHARTIER, Roger. A história cultural: entre práticas e representações. Lisboa: Difel, 1990.

CHOPPIN, Alain. 0 historiador e o livro escolar. Revista História da Educação, Pelotas, v. 6, n. 11, p. 5-24, abr. 2002.

DARNTON, Robert. 0 beijo de Lamourette: mídia, cultura e revolução. São Paulo: Companhia das Letras, 1990.

D’ÁVILA, Antônio. Literatura infanto-juvenil. São Paulo: Editora do Brasil, 1964. (Coleção didática do Brasil. Série normal; v. 20).

FERREIRA, Norma Sandra de Almeida. As cartilhas de João Köpke para o ensino da leitura. Revista Brasileira de Alfabetização, Vitória, v. 1.n. 1, p. 155-176, jan./jun. 2015.

FERREIRA, Norma Sandra de Almeida. Um estudo sobre "Versos para os pequeninos", manuscrito de João Köpke, 2014. 315f. Tese (Livre-Docência) - Faculdade de Educação da Universidade Estadual de Campinas, Campinas, 2014.

FERREIRA, Norma Sandra de Almeida; SANTOS, Maria Lygia Cardoso Köpke. 0 Livro de Hilda" (1902), a cartilha do método analítico, por João Köpke. Pró-Posições, Campinas, v. 25, n. 3, (75), p. p. 185-209, set./ dez. 2014.

FRADE, Isabel Cristina da Silva. Cartilha Proença e leitura do principiante de Antonio Firmino Proença: configurações gráficas e pedagogia. In: RAZZINI, Márcia de Paula Gregório. Antonio Firmino de Proença: professor, formador, autor. São Paulo: Porto de Ideias, 2010a. Cap. 6, p. 141-167.

FRADE, Isabel Cristina da Silva. Livros para ensinar a ler e escrever: uma pequena análise da visualidade de livros produzidos no Brasil, em Portugal e na França, entre os séculos XIX e XX. In: BRAGANÇA, Aníbal; ABREU, Márcia de Paula Gregório. Impresso no Brasil: dois séculos de livros brasileiros. São Paulo: Unesp, 2010b. Cap. 9, p. 171- 190.

GOULART, Ilsa do Carmo Vieira. 0 livro: objeto de estudo e memória de leitura, 2009. 282f. Dissertação (Mestrado em Educação) - Faculdade de Educação da Universidade de Campinas, Campinas, 2009. 
HALLEWELL, Laurence. 0 livro no Brasil: sua história. 2. ed. Tradução de Maria da Penha Villalobos e Lólio Lourenço de Oliveira. São Paulo: Edusp, 2005.

HILSDORF, Maria Lúcia Spedo. Francisco Rangel Pestana: jornalista, político, educador, 1986. 343f. Tese (Doutorado em Educação) - Faculdade de Educação da Universidade de São Paulo, São Paulo, 1986.

LAGUNA, Shirley Puccia. Uma leitura dos livros de leitura da Escola Americana de São Paulo (1889-1933), 2003. 220f. Tese (Doutorado em Educação) - Pontifícia Universidade Católica de São Paulo, São Paulo, 2003.

KÖPKE, João. A grande pátria. Rio de Janeiro: Typ. Do Jornal do Commercio de Rodrigues \& Comp, 1900a. (Amarilio de Vasconcellos).

KOPKE. João. A poesia nas escolas (Um livro de Zalina Rolim). A Província de São Paulo, São Paulo, p. 1., 28 jan. 1896.

KÖPKE, João. Carta prefácio à Sra. Presciliana Duarte de Almeida (1907). In: ALMEIDA, P. D. Páginas Infantis: XIII Milheiro. São Paulo, Escolas Profissionaes Salesianas, 1914. p. xxxii-xliii.

KÖPKE. João. Crítica sobre trabalhos escolares - Ensino da Leitura (Carta aos professores Joaquim Luiz de Britto e Ramon Roca Dordal). Revista de Ensino, São Paulo, n. 4, v. I, p. 772, 1902.

KÖPKE, João. Curso de língua materna: notas para a sua direcção. São Paulo: Teixeira, 1892. 114 p. Obras raras. (Acervo: Coleção Oficina do Livro "Rubens Borba de Moraes", Biblioteca Central "Cesar Lattes", Universidade Estadual de Campinas).

KÖPKE, João. Leituras práticas. 7. ed. Rio de Janeiro: Livraria Francisco Alves, 1909a.

KÖPKE, João. Fábulas: para uso das classes de lingua materna. Instituto Henrique Köpke. 3. ed. Rio de Janeiro: Livraria Francisco Alves, 1910.

KÖPKE, João. Florilégio contemporâneo: quinto livro de leitura para uso das escolas secundárias. 2. ed. São Paulo: Miguel Melillo, 1900b. Adaptada ao Curso Systematico da Lingua Materna. (Collecção de João Köpke - Série Rangel Pestana).

KÖPKE, João. Locuções, proloquios e pensamentos: ampliação do vocabulário e exercício da memória para uso das escolas primarias e secundarias - Curso Systematico da Lingua Materna. Rio de Janeiro: [s. n.], 1915. $172 \mathrm{p}$.

KÖPKE, João. Primeiro livro de leituras moraes e instructivas para uso das escolas primarias e secundarias. 64. ed. Rio de Janeiro: Francisco Alves, 1923. 168 p. Illustrada, revista pelo autor e adaptada ao Curso Systematico da Lingua Materna. (Collecção de João Köpke - Série Rangel Pestana).

KÖPKE, João. Quarto livro de leituras moraes e instructivas para uso das escolas primarias e secundarias. 6. ed. Rio de Janeiro: Francisco Alves, 1909b. Adaptada ao Curso Systematico da Lingua Materna. (Collecção de João Köpke - Série Rangel Pestana). 
KÖPKE, João. Segundo livro de leituras moraes e instructivas para uso das escolas primarias e secundarias. 58. ed. Rio de Janeiro: Francisco Alves, 1926. 232 p. Illustrada, revista pelo autor e adaptada ao Curso Systematico da Lingua Materna. (Colecção de João Köpke - Série Rangel Pestana).

KÖPKE, João. Terceiro livro de leituras moraes e instructivas para uso das escolas primarias e secundarias. 43. ed. Rio de Janeiro: Francisco Alves, 1922. 347 p. Revista pelo autor e adaptada ao Curso Systematico da Lingua Materna. (Collecção de João Köpke - Série Rangel Pestana).

KÖPKE, João. Versos para os pequeninos: pelo director do Instituto Henrique Köpke. [s.n.t.]. p. 54. Manuscrito original.

LAJOLO, Marisa; ZILBERMAN, Regina. A formação da leitura no Brasil. 3. ed. São Paulo: Ática, 1999. 374 p.

LAJOLO, Marisa; ZILBERMAN, Regina. Literatura infantil brasileira: histórias e histórias. São Paulo: Ática, 1988.

MENESES, João Gualberto de Carvalho. Discurso de posse do acadêmico João Gualberto de Carvalho Meneses. São Paulo, Academia Paulista de Educação, 1980. Disponível em: <http://www.apedu.org. br/home/index.php?option=com_content\&view=article\&id=129:discurso-de-saudacao-ao-academicomoacyr-expedito-marret-vaz-guimaraes\&catid=10:discursos\&ltemid=171 >. Acesso em: 10 out. 2012.

MORTATTI, Maria do Rosário Longo. Os sentidos da alfabetização: São Paulo - 1876/1994. São Paulo: Unesp; Brasillia, DF: MEC/Inep/Comped, 2000.

OLIVEIRA, Cátia Regina Guidio Alves; SOUZA, Rosa Fatima. As faces do livro de leitura. Cadernos Cedes, Campinas, v. 19, n. 52, p. 25-40, nov. 2000.

ORIANI, Angélica Pall. Série "Leituras infantis" (1908-1919) de Francisco Vianna e a história do ensino de leitura no Brasil, 2010. Dissertação (Mestrado em Educação) - Faculdade de Filosofia e Ciências da Universidade Estadual Paulista "Júlio de Mesquita Filho" - Unesp, Marília, 2010.

PANIZZOLO, Claudia. João Köpke e a escola republicana: escritor de leitura, escritor da modernidade, 2006. 335f. Tese (Doutorado em Educação) - Pontifícia Universidade Católica de São Paulo, São Paulo, 2006.

PERES, Eliane Teresinha; TAMBARA, Elomar (Org.). Livros escolares e ensino da leitura e da escrita no Brasil. Pelotas: Seiva, 2003.

PETRUCCI, Armando. La escritura manuscrita y la imprenta: ruptura o continuidad. In: PETRUCCI, Armando. Alfabetismo, escritura, sociedade. Tradução Juan Carlos Gentile Vitale. Barcelona: Geedisa, 1999. p. 117-128.

PFROMM NETO, Samuel; ROSAMILHA, Nelson; DIB, Claudio Zaki. 0 livro na educação. Rio de Janeiro: Primor: MEC, 1974.

PIZA, Maria Amélia Blasi de Toledo. Zalina Rolim: poetisa e educadora. Itu: Ottoni, 2008. 
RAZZINI, Maria Paula Gregorio. 0 espelho da Nação: a "Antologia Nacional" e o ensino de português e literatura (1838-1971), 2000. Tese (Doutorado em Estudos da Linguagem) - Instituto de Estudos da Linguagem da Universidade de Campinas, Campinas, 2000.

RIBEIR0, Neucinéia Rizzato. Um estudo sobre a leitura analytica (1896), de João Köpke, 2001. 66f. Monografia (Trabalho de Conclusão de Curso em Educação) - Faculdade de Filosofia e Ciências da Universidade Estadual Paulista "Júlio de Mesquita Filho - Unesp, Marília, 2001.

ROLIM, Zalina. Livro das crianças (1897). Edição fac-símile. In: PIZA, Maria Amélia Blasi de Toledo. Zalina Rolim: poetisa e educadora. Itu: Ottoni, 2008.

SANTOS, Maria Ligia Cardoso Köpke. Lendo com Hilda: João Köpke - 1902, 2013. Tese (Doutorado em Educação) - Universidade Estadual de Campinas, Campinas, 2013.

Recebido em: 24.03.2016

Aprovado em: 03.11.2016

Norma Sandra de Almeida Ferreira é professora livre-docente da Faculdade de Educação da Universidade Estadual de Campinas. Coordenadora do grupo de pesquisa Alfabetização, Leitura e Escrita (ALLE/FE/Unicamp). 